\title{
Categorization of the main descriptors of different ampicillin crystal habits
}

\author{
Oscar Flórez-Acosta ${ }^{1, *}$, Gloria Tobón-Zapata1, Jaime Valencia-Velasquez² \\ ${ }^{1}$ Department of Pharmacy, Faculty of Pharmaceutical Chemistry, University of Antioquia, ${ }^{2}$ Department of Electric \\ Engineering, Faculty of Engineering, University of Antioquia
}

\begin{abstract}
With the purpose of enabling the analysis by digital methods of particles of multisource pharmaceutical raw materials, this study analyzed different crystal habits of ampicillin particles, by grouping the external shapes obtained from 3 different solvents (acetonitrile, ethanol, and methanol), thereby reducing the number of descriptors necessary to adequately represent each shape. For this purpose, a selection of morphological descriptors was used including: circularity, roughness, roundness, compactness, aspect ratio, effective diameter, solidity, convexity, fractal dimension, and 10 Complex Fourier descriptors. These measures cover highly diverse morphological properties and define the crystal habit of a particle. Principal Component Analysis (PCA) and the Cluster Analysis (CA) were the grouping techniques used, which demonstrated the possibility of using between 2 and 4 descriptors instead of the 18 proposed initially.
\end{abstract}

Uniterms: Multisource solids. Morphological descriptors. Fourier descriptors. Crystal habits. Multivariate analysis.

\begin{abstract}
Com o objetivo de possibilitar a análise, por meio de métodos digitais, de partículas de matérias-primas farmacêuticas de múltiplas fontes, analisaram-se diferentes cristais de partículas de ampicilina através do agrupamento de formas externas obtidas de três diferentes solventes (acetonitrila, etanol e metanol), reduzindo, desse modo, o número de descritores necessários para representar adequadamente cada forma. Com esse propósito, utilizou-se seleção de descritores morfológicos, incluindo: circularidade, aspereza, arredondamento, compactação, relação de aspecto, diâmetro efetivo, solidez, convectividade, dimensão fractal e 10 descritores complexos de Fourier. Essas medidas cobrem diversas propriedades morfológicas e definem a cristalinidade de uma partícula. As análises do componente principal (PCA) e por grupamento (CA) foram as técnicas de agrupamento utilizadas, que demonstraram a possibilidade de utilizar entre 2 e 4 descritores ao invés dos 18, inicialmente propostos.
\end{abstract}

Unitermos: Sólidos de múltiplas fontes. Descritores morfológicos. Descritores Fourier. Cristal. Análise multivariada

\section{INTRODUCTION}

Ampicillin is one of the most widely used antiinfective agents in the world. This antibiotic, and other multisource active pharmaceutical ingredients (API), are marketed by different companies and have reported variations in bioavailability. However, controversy exists in studies over the best absorption between anhydrous or trihydrate species, 2 reported structural forms of ampi-

\footnotetext{
*Correspondence: O. Flórez-Acosta. Departamento de Farmacia, Facultad de Química Farmacéutica-UdeA. Clle 67 N53-108, B2-127, Medellín, Colombia. E-mail: oflorez@farmacia.udea.edu.co
}

cillin. Although these authors state that the formulation plays an important role, it is likely that the size and shape of the particles is a factor that should be taken into account (Cabana, Willhitc, Bierwagen, 1969; Hill et al., 1975; Ali, Farouk, 1981).

There are several factors that can influence the formation of anhydrous or hydrate forms (Zhu, Yuen, Grant, 1995; Zhu, Grant, 1996; Nojavan et al., 2005), however, the formation of these chemical species has not shown a direct relationship with the external form of the particles. Nevertheless, these differences in crystal habits have been found to depend on the diverse environment of crystalgrowing conditions, such as supersaturation, temperature, 
agitation, solvents and cosolvents, existence of cosolutes, and adsorbable foreign ions, as well as the milling processes (Haleblian, 1975).

The aim of this study was to further the decision on an adequate strategy to simplify the routine measurement of the solid raw material crystalline habits derived from different manufacturers, given that the morphology of these particles can be described using different techniques and approaches, and there is no clear consensus on which are the most appropriate. In this case, different crystal habits of ampicillin were used as a model.

Patience and James used an algorithm that allows, by means of digital analysis, controlling and monitoring of the crystallization process in real time, using a micrometer to measure the size and aspect ratio and a boxed area to provide a description of particle shape (Patience, Rawlings, 2001). However, the overriding consensus holds that the morphology of a particle cannot be characterized using only one descriptor, especially with APIs whose origin is not known or that have been exposed to comminution, since it is necessary to define at least the geometrical shape, surface roughness, and angularity. Hence, simultaneous use of several of these descriptors becomes inevitable (Barret, 1980; Podczeck, Newton, 1995).

The interpretation of the morphological measurements of the particles through digital analysis remains complicated, hence this study's use of classic morphological descriptors that highlight the characteristics of the edges of the figure, for ease of measurement and interpretation, and the use of descriptors based on mathematic methods that integrally define the particles.

The classic measurement methods used were: the circularity shape factor, which combines the roughness and symmetry of the contours; roundness, that measures the difference between the particle surface and a circular surface, with a maximum Feret diameter, and compares the angularity and texture; the curvature of the particles was also measured through compactness; the aspect ratio, represents the irregularity of the particle, since it relates the length and width; the effective diameter, with which the particle is approximated to a sphere averaged by the maximum and minimum diameter; solidity, describes the convexity of the polygon that defines the contour; and convexity, that compares the perimeter of the curvatures regarding the polygon, as an angularity measure.

Also, mathematic descriptors were calculated as the fractal dimension and Fourier transform complex. Both methods may be used to perform a structural measurement of the particle figure (Ehrlich, Weimberg, 1970).

The Fractal Dimension is more a solidness and texture measurement than a shape measurement. In this case the method used for its measurement is called "box counting". The irregularity of the particles is obtained through the length of the "box", i.e. the measurement of the perimeter of the contour. This process is repeated for boxes from 2 to 64 pixels wide, then the size log is plotted against the box amount log, and the slope is considered as the measurement for the fractal dimension (Biswas et al., 1998).

For the measurement of Fourier transform, the method used was Fourier complex descriptors, where each of these can explain different parameters of the shape (Clark, 1981).

Finally, to carry out categorization of the classic and mathematic shape descriptors, 2 multivariate analysis techniques were used: Principal Components Analysis (PCA), used to reduce the number of correlated variables between them, simplifying or classifying complex data, such as the case of the different ampicillin solids obtained, retaining the highest possible amount of variation of each data series; and the results were reinforced by a hierarchic Cluster Analysis (CA), which enables the pooling of different sets of observations based on the similarities among them (Maciejewski, Roberts, 2001; Berthiaux et al., 2006; Kaufman, Rousseeuw, 1990). These techniques enabled reorganization of all the descriptors used, and enables the subsequent use of a subset of them (Pons, 2002).

\section{MATERIALS AND METHODS}

Ampicillin as a raw material was kindly donated by a pharmaceutical industry and used in the form received. Analysis showed water content of $12-15 \%$, which indicated occurrence of trihydrate ampicillin (USP31, 2007). Subsequently, the solid was dissolved in solvent to boiling point, immediately filtrated, and the hot supersaturated solution allowed to reach room temperature, then cooled $\left(10-15^{\circ} \mathrm{C}\right)$ until the formation of crystals. Acetonitrile $(\mathrm{ACN})$, ethanol (EtOH), and methanol (MetOH) solvents (all solvents were JT Baker $\AA$, reactive grade) were chosen because they produced different crystalline shapes.

From the crystals obtained, 9 representative recrystallized ampicillin microphotographs were selected: 3 in acetonitrile, 3 in ethanol, and 3 in methanol. The images were binary converted for the analysis, as shown in Figure 1 (Mateu, Lorenzo, 2002). The measurements and the digital processing were done with Matlab $7^{\circledR}$ (THE MATHWORKS INC. Massachusetts, 2004), ImageJ 1.41 (Rasband, 2009), and Lispix 137P (Bright, 2008) programs.

All the descriptors used are invariant with regard to particle size as shown in Table 1: The circularity shape 


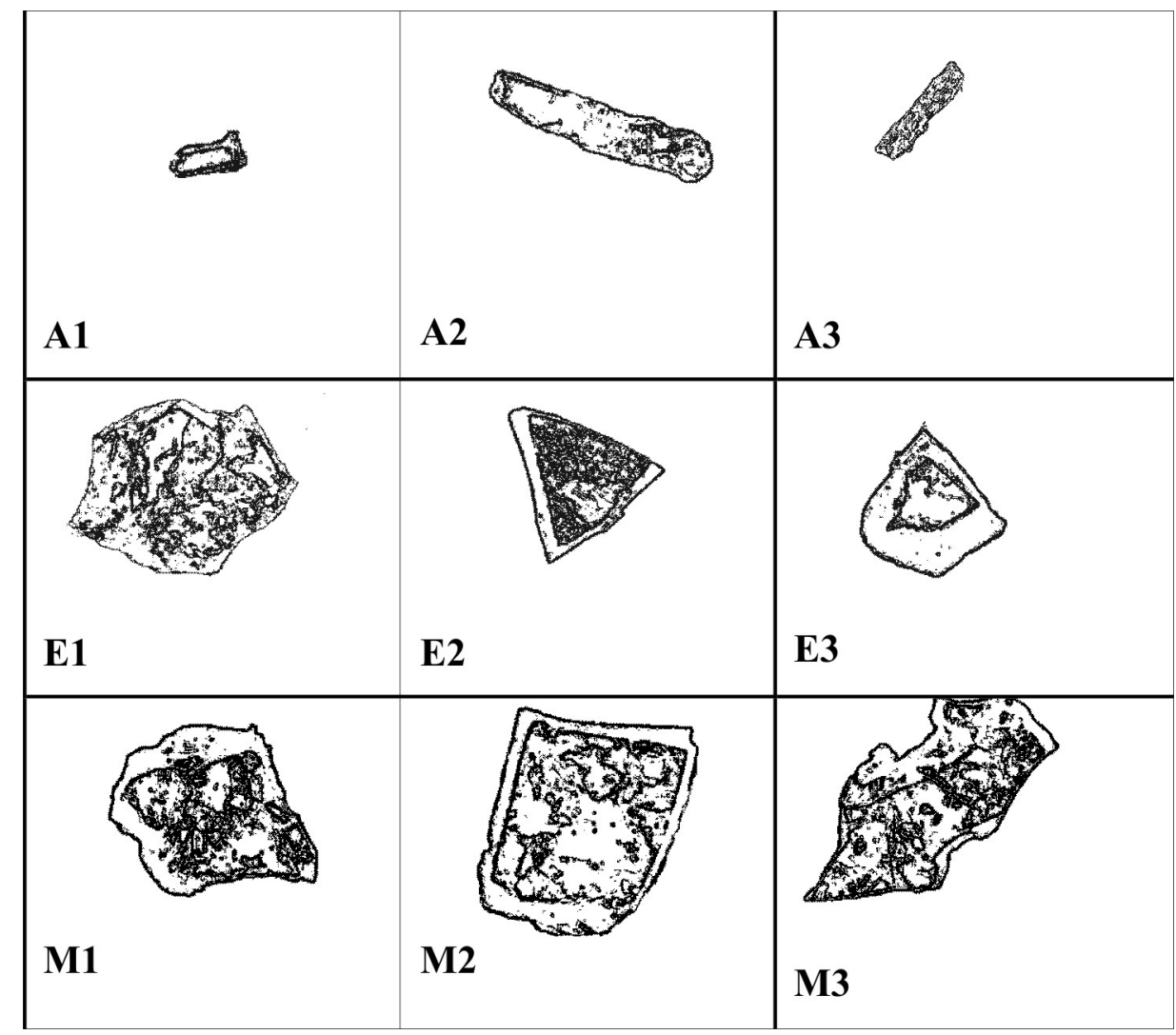

FIGURE 1 - Microphotographs taken with 10x objective, converted to binary format for measurement. Letters correspond to the solvent: $\mathrm{A}_{(\mathrm{i})}$, for acetonitrile; $\mathrm{E}_{(\mathrm{i})}$, for ethanol; $\mathrm{M}_{(\mathrm{i})}$, for methanol.

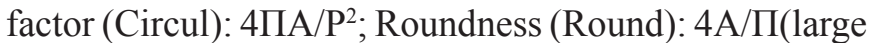
axis $)^{2}$; Compactness (Comp): $(4 \mathrm{~A} / \Pi)^{1 / 2} /$ large axis; Aspect ratio (AR): large axis/Minor axis; Effective Diameter (Eff_ Diam): $2(\mathrm{~A} / \Pi)^{1 / 2}$; Solidity (Solidity): A/Convex A; Convexity (Convexity): $\mathrm{Pc} / \mathrm{P}$; with $\mathrm{A}=$ area in squared pixels, $\mathrm{P}=$ perimeter, measured as the length of the external edge of the particle, $\mathrm{Pc}=$ convex perimeter. Fractal Dimension (Dfractal): $\mathrm{D}_{\mathrm{F}}=\log \left(\mathrm{N}_{\varepsilon} / \log \varepsilon\right)$; where $\mathrm{N}$, is the number of boxes and $\varepsilon$ is the scale. The slope of the regression line was the fractal dimension (D).

As Fourier Complex descriptors (see equation 1), the first 10 coefficients were calculated (DFC0, DFC1, DFC2, DFC3, DFC4, DFC5, DFC6, DFC7, DFC8, and DFC9). The method uses all the points that make up the completely full particle (Raadnui, 2005; Bowman, Kenichi, Drummond, 1997).

$x_{m}+i y_{m}=\sum_{n=-N / 2+1}^{+N / 2}\left(a_{n}+i b_{n}\right)\left[\cos \left(\frac{2 \pi n m}{M}\right)+i \sin \left(\frac{2 \pi n m}{M}\right)\right]($ Eq. 1)

Eq. 1: Where $x$ and $y$ are the coordinates that describe each of the pixels of the particle; $N$, is the total number of coefficients; $M$, is the total number of pixels used in the particle description; $m$, is the number of each of the points; $a, b$, are the coefficients of each factor; i, marks an imaginary number.

The PCA and CA multivariate analyses were conducted with the Statgraphics Centurion XV program for Windows (Statistical Graphics Co., Rockville, MD, USA. 2007).

\section{RESULTS AND DISCUSSION}

The PCA data depicted in Table II and the scree plot in Figure 2 were obtained based on the measurement of the descriptors of the 9 particles, with linear combination of the 18 descriptors which combined gave the total variability of the data. It was found that taking 2,3 , or 4 components yielded eigenvalues greater than 1 and cumulated variability percentages greater than $75 \%$.

Figure 3 evidences low weight in the matrix component correlation. Therefore, an evaluation of the correlation among all the pairs of variables through the Pearson Moment Product test was performed, and statistical significance with $95 \%$ confidence was found. 
TABLE I - Values of the descriptors of each of the particles: A1, A2, A3 (recrystallized in acetonitrile); E1, E2, E3 (in ethanol); M1, M2, M3 (in methanol)

\begin{tabular}{lccccccccc}
\hline & A1 & A2 & A3 & E1 & E2 & E3 & M1 & M2 & M3 \\
\hline Circul. & 0.58 & 0.40 & 0.38 & 0.69 & 0.63 & 0.68 & 0.68 & 0.70 & 0.54 \\
Round & 0.43 & 0.20 & 0.23 & 0.81 & 0.85 & 0.97 & 0.82 & 0.79 & 0.48 \\
Comp & 0.65 & 0.45 & 0.48 & 0.90 & 0.92 & 0.99 & 0.90 & 0.89 & 0.69 \\
AR & 2.33 & 4.97 & 4.28 & 1.23 & 1.17 & 1.03 & 1.22 & 1.26 & 2.07 \\
Ef Diam & 48.45 & 104.31 & 107.08 & 202.92 & 140.09 & 143.05 & 180.71 & 219.96 & 192.21 \\
Solidity & 0.88 & 0.91 & 0.88 & 0.94 & 0.94 & 0.95 & 0.92 & 0.95 & 0.88 \\
Convex & 0.93 & 0.94 & 0.88 & 0.89 & 0.94 & 0.91 & 0.91 & 0.91 & 0.89 \\
Dfractal & 15.926 & 16.737 & 16.487 & 18.215 & 17.876 & 17.998 & 17.249 & 18.712 & 17.880 \\
DFC0 & 197.57 & 198.73 & 121.17 & 188.55 & 199.06 & 207.30 & 203.23 & 206.34 & 172.44 \\
DFC1 & 4.81 & 27.27 & 31.29 & 21.75 & 8.93 & 16.86 & 27.79 & 3.14 & 33.81 \\
DFC2 & 3.37 & 13.81 & 14.10 & 15.94 & 9.38 & 10.13 & 11.23 & 15.68 & 17.89 \\
DFC3 & 2.38 & 10.33 & 10.37 & 1.02 & 5.86 & 7.67 & 7.91 & 10.41 & 10.99 \\
DFC4 & 1.90 & 7.37 & 7.36 & 7.74 & 4.82 & 5.88 & 5.74 & 7.56 & 6.92 \\
DFC5 & 1.66 & 6.46 & 0.60 & 5.62 & 4.08 & 5.04 & 4.03 & 6.19 & 5.59 \\
DFC6 & 1.29 & 4.83 & 5.14 & 4.80 & 3.57 & 4.18 & 3.10 & 4.85 & 5.40 \\
DFC7 & 0.00 & 4.63 & 4.23 & 0.38 & 3.24 & 3.63 & 2.65 & 4.00 & 5.13 \\
DFC8 & 0.00 & 4.02 & 3.72 & 3.36 & 0.27 & 0.32 & 2.19 & 3.44 & 4.25 \\
DFC9 & 0.00 & 3.36 & 3.30 & 3.03 & 2.55 & 0.27 & 2.00 & 2.82 & 3.58 \\
\hline
\end{tabular}

TABLE II - Eigenvalues and cumulated percentage for the 4 principal components

\begin{tabular}{cccc}
\hline $\begin{array}{c}\text { Component } \\
\text { Number }\end{array}$ & Eigenvalue & $\begin{array}{c}\text { Percent of } \\
\text { Variance }\end{array}$ & $\begin{array}{c}\text { Cumulative } \\
\text { Percentage }\end{array}$ \\
\hline 1 & 7.47742 & 41.541 & 41.541 \\
2 & 6.22821 & 34.601 & 76.142 \\
3 & 1.81638 & 10.091 & 86.233 \\
4 & 1.00281 & 5.571 & 91.805 \\
\hline
\end{tabular}

According to the PCA data in Table III and bi-plot of Figure 3, the first component directly correlated with circularity, roundness, compactness, solidity, convexity, fractal dimension, and DFC5, DFC6, and DFC7, and has an inverse correlation with the other descriptors; the second component presents a direct correlation with the aspect ratio and convexity; the third component correlated with the aspect ratio, solidity, convexity, Dfractal, DFC1, DFC3, DFC6, and DFC7, the effective diameter and DFC0, DFC3, DFC5, DFC6, and DFC7; the fourth component, correlated with the roundness, compactness, Dfractal, DFC1, DFC3, DFC6, and DFC7. Effective diameter and DFC2 have no positive correlation with any of the 4 selected components.

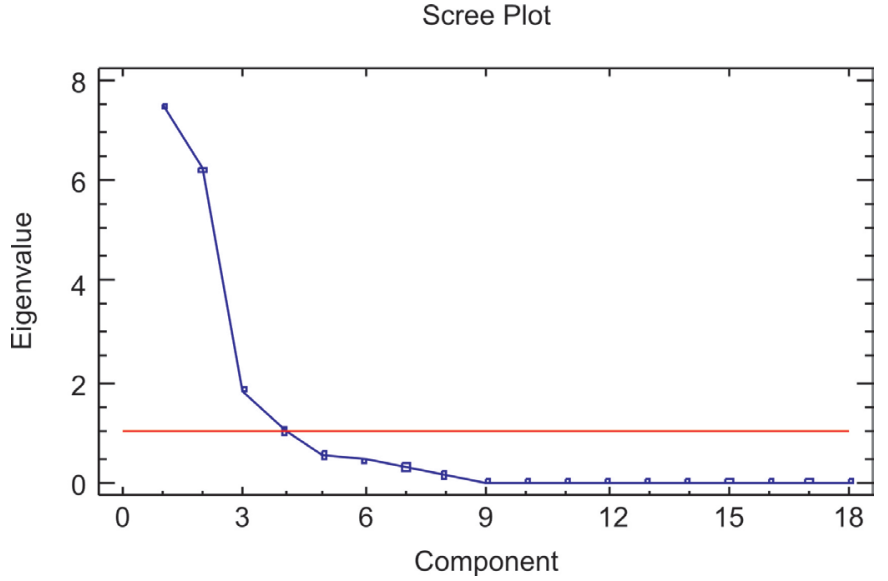

FIGURE 2 - Eigenvalues obtained from the 18 total components. The red line indicates the 4 principal components.

The 4 components may be defined according to the information that they represent: the first can be taken as compacting, density, or homogeneity, given their topological intuitive notion; the second component, could be considered the stretching or elongation factor; the third, is present in particles that do not have "entries" or "bays" and therefore represents smoothing of edges; the fourth, can be an indication of angularity.

To consolidate the decrease in variables, the CA 
TABLE III - Weight of individual descriptors for the 4 principal components

\begin{tabular}{lcccc}
\hline & Component 1 & Component 2 & Component 3 & Component 4 \\
\hline Circularity & 0.277369 & -0.241803 & -0.129708 & -0.00162119 \\
Round & 0.254452 & -0.265087 & -0.100107 & 0.184307 \\
Comp & 0.257691 & -0.264178 & -0.119644 & 0.172624 \\
AR & -0.263451 & 0.23001 & 0.207803 & -0.160283 \\
Eff_Diam_ & -0.0345004 & -0.381239 & -0.124758 & -0.0271656 \\
Solidity & 0.174857 & -0.289978 & 0.170145 & -0.033214 \\
Convexity & 0.171049 & 0.115263 & 0.585774 & -0.137735 \\
Dfractal & 0.0455326 & -0.387928 & 0.0110799 & 0.0580205 \\
DFC0 & 0.259163 & -0.129341 & 0.392043 & -0.19182 \\
DFC1 & -0.275044 & -0.00309454 & -0.171332 & 0.0309199 \\
DFC2 & -0.263786 & -0.268928 & -0.0672345 & -0.117838 \\
DFC3 & -0.246004 & -0.0672701 & 0.298447 & 0.549822 \\
DFC4 & -0.260831 & -0.0101221 & -0.118506 \\
DFC5 & -0.253714 & -0.299737 & 0.376831 & -0.309024 \\
DFC6 & -0.0123045 & -0.234292 & 0.00629008 & 0.0310601 \\
DFC7 & -0.106836 & 0.328284 & 0.534266 \\
DFC8 & -0.278146 & -0.126164 & -0.0286414 & -0.281576 \\
DFC9 & -0.242226 & -0.147227 & 0.0226444 & -0.239145 \\
\hline
\end{tabular}

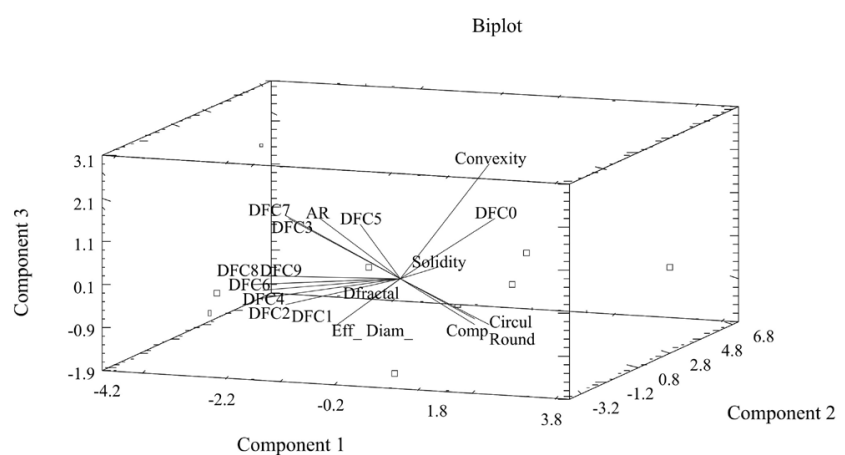

FIGURE 3 - Shows the position of the 18 descriptors and 9 particles showing the relationships of descriptors among the 3 most important components.

(Ward method) was applied, evaluating the Euclidean distance between the weight of the descriptors of the 4 main components chosen, and represented in the dendrogram of Figure 4. This formed the following groups: the first comprising circularity, roundness, compactness, solidity, effective diameter, DFractal and DFC5; the second made up of AR, DFC1, DFC3 and DFC7; the third formed by convexity and DFC0; and the fourth by DFC2, DFC4, DFC6, DFC8, and DFC9.

The groups obtained in the PCA and CA revealed the following common descriptors: circularity, roundness,

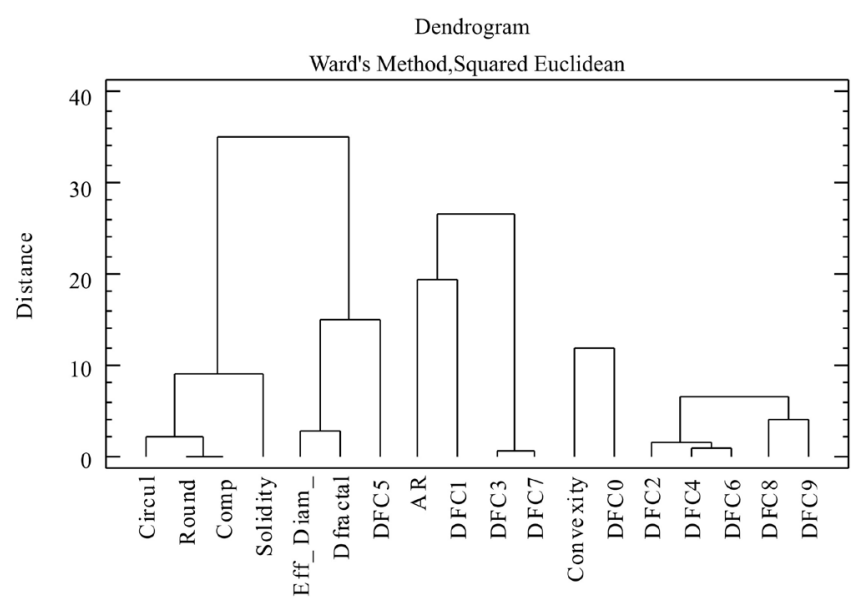

FIGURE 4 - Dendrogram showing groupings of the variables on the conglomerate analysis by the Ward Method, using squared Euclidean as metric distance.

compactness, solidity and Dfractal, for the first group; AR, and $\mathrm{DFC} 1$ for the second group; convexity and $\mathrm{DFC} 0$, for the third; and only DFC6 for the fourth group.

The results demonstrated that for adequate characterization it is convenient to measure a maximum of 4 parameters, possibly yielding more information than other systems with less descriptors that are commonly used, for example: roundness, roughness, and angularity. However, 
TABLE IV - Composition of each component based on correlation weight per recrystallized particle

\begin{tabular}{llcccc}
\hline Row & Label & Component 1 & Component 2 & Component 3 & Component 4 \\
\hline 1 & A1 & 3.43907 & 4.86365 & -0.314655 & -0.48314 \\
2 & A2 & -2.93279 & 1.30271 & 2.64899 & -1.06917 \\
3 & A3 & -4.19958 & 2.4373 & -1.55551 & 0.835978 \\
4 & E1 & 0.552899 & -2.34755 & -1.8059 & -1.94641 \\
5 & E2 & 2.32354 & -0.239497 & 0.807302 & 0.412514 \\
6 & E3 & 2.36611 & -1.17864 & 0.249318 & 1.27983 \\
7 & M1 & 1.14089 & -0.50668 & -0.467935 & 0.351352 \\
8 & M2 & 0.317966 & -3.15023 & 0.812943 & 0.176611 \\
9 & M3 & -3.0081 & -1.18105 & -0.374556 & 0.442439 \\
\hline
\end{tabular}

besides the information obtained from the PCA, a faster approximation for morphological characterization is possible using only 2 of these descriptors (but with greater loss of information), for example: DFC0 and DFC3, with complex Fourier descriptors; or compactness and convexity, if only classic shape descriptors are used (Almeida-Prieto, Blanco-Méndez, Otero-Espinar, 2007; Powers, 1953).

Table IV constitutes a base to classify the different types of re-crystallized ampicillin particles: compact shapes, A1, E1, E2, E3, M1, M2; elongated, A1, A2, A3; with smooth edges, A2, E2, E3, M2; and with angle shapes, A3, E2, E3, M1, M2, M3. It must be considered that the different descriptors are greater or least measure weighted in each of the components, for example: A1, is not smooth, and does not have angles; E2, is not elongated, but compact, smooth, and angular.

\section{CONCLUSIONS}

Other articles make reference to the use of at least 3 descriptors to define the morphology of a bi-dimensionally observed particle. However, it may be inferred from the results obtained in ampicillin particles re-crystallized in different solvents, and through the use of multivariate techniques of PCA and CA, that this number can be reduced to a minimum of 2 descriptors. Nevertheless, to achieve a better approximation in the morphological definition it is necessary to use 4 descriptors.

Finally, using this recrystallization technique, the analysis showed that the ampicillin habit in acetonitrile are mainly elongated, those recrystallized in ethanol were compact, smooth, and with angles, while particles recrystallized in methanol were very similar to those in ethanol, only rougher.

\section{REFERENCES}

ALI, A.; FAROUK, A. Comparative studies on the bioavailability of ampicillin anhydrate and trihydrate. Int. J. Pharm., v.9, n.3, p.239-243, 1981.

ALMEIDA-PRIETO, S.; BLANCO-MÉNDEZ, J.; OTEROESPINAR, F. Microscopic image analysis techniques for the morphological characterization of pharmaceutical particles: Influence of the software, and the factor algorithms used in the shape factor estimation. Eur. J. Pharm. Biopharm., v.67, n.3, p.766-776, 2007.

BARRET, P. The shape of rock particles, a critical review. Sedimentology, v.27, n.3, p.291-303, 1980.

BERTHIAUX, H.; MOSOROV, V.; TOMCZAK, L.; GATUMEL, C.; DEMEYRE, J.F. Principal component analysis for characterising homogeneity in powder mixing using image processing techniques. Chem. Eng. Pro., v.45, n.5, p.397-403, 2006.

BISWAS, M.K; GHOSE, T.; GUHA, S.; BISWAS, P. K. Fractal dimension estimation for texture images: A parallel approach. Patt. Recog. Lett., v.19, n.3-4, p.309-313, 1998.

BOWMAN, E.; SAGA, K.; DRUMMOND, T. Particle shape characterisation using Fourier analysis. Geotechnique (CUED/D-Soil/TR315), v.51, n.6, p.545-554, 2001.

CABANA, B.E.; WILLHITC, L.E.; BIERWAGEN, M.E. Pharmacokinetic evaluation of the oral absorption of different ampicillin preparations in beagle dogs. Antimicrob. Agents Chemother., v.9, n.1, p.35-41, 1969. 
CLARK, M. W. Quantitative shape analysis: a review. Math. Geol., v.13, n.4, p.303-320, 1981.

EHRLICH, R.; WEINBERG, B. An exact method for characterization of grain shape. J. Sediment. Petrol., v.40, n.1, p.205-212, 1970.

HALEBLIAN, J. Characterization of habits and crystalline modification of solids and their pharmaceutical applications. J. Pharm. Sci., v.64, n.8, p.1269-1288, 1975.

HILL, S.A.; JONES, K.H.; SEAGER, H.; TASKIS, C.B. Dissolution and bioavailability of anhydrate and trihydrate ampicillin. J. Pharm. Pharmacol., v.27, n.8, p.594-598, 1975.

KAUFMAN, L.; ROUSSEEUW, P.J. Finding groups in data: an introduction to cluster analysis. New York: Wiley \& Sons, Inc., 1990.368 p.

MACIEJEWSKI, A.A.; ROBERTS, R.G. An example of principal component analysis applied to correlated images. In: SOUTHEASTERN SYMPOSIUM ON SYSTEM THEORY, 33., Athens, 2001. Proceedings. Ohio: Colorado State University, Libraries, 2001. p.269-273.

MATEU, J.; LORENZO, G. Detección de rasgos en imágenes binarias mediante procesos puntuales Espaciales marcados. Qüestiió, v.26, n.1-2, p.61-85, 2002.

NOJAVAN, S.; GHASSEMPOUR, A.; BASHOUR, Y.; DARBANDI, M.; AHMADI, S. Determination of residual solvents and investigation of their effect on ampicillin trihydrate crystal structure. J. Pharm. Biomed. Anal.,v.36, n.5, p.983-988, 2005.

PATIENCE, D.B.; RAWLINGS, J.B. Particle-Shape Monitoring and Control in Crystallization Processes. AIChE Journal., v.47, n.9, p.2125-2130. 2001.
PODCZECK, F.; NEWTON, J.M. The evaluation of a threedimensional shape factor for the quantitative assessment of the sphericity and surface roughness of pellets. Int. J. Pharm., v.124, n.2, p.253-259, 1995.

PONS, M.N.; VIVIER, H.; DELCOUR, V.; AUTHELIN, J. R.; PAILLÉRES-HUBERT, L. Morphological analysis of pharmaceutical powders. Powd. Tech., v.128, n.2-3, p.276286, 2002.

POWERS, M. A new roundness scale for sedimentary particles. J. Sediment. Petrol., v.23, n.2, p.117-119, 1953.

RAADNUI, S. Wear particle analysis. Utilization of quantitative computer image analysis: A review. Tribol. Int., v.38, n.10, p.871-878, 2005.

THE UNITED STATES PHARMACOPEIA. 31. The National Formulary 26. Monographs: Ampicillin, water, Method I $<921>$. ed. Rockville: United States Pharmacopeial Convention, 2007. 517 p.

ZHU, H..; YUEN, C.; GRANT, D. Influence of water activity on the anhydrate and hydrate phases of ampicillin crystallized from methanol + water mixtures. Pharm. Res., v.12, n.9, p.S-196 PDD 7016, 1995.

ZHU, H.; GRANT, D. Influence of water activity in organic solvent + water mixtures on the nature of the crystallizing drug phase: 2. Ampicillin. Int. J. Pharm., v.139, n.1-2, p.33-43, 1996.

Received for publication on $04^{\text {th }}$ May 2009. Accepted for publication on $19^{\text {th }}$ May 2010. 